Relato de experiência

\title{
Conhecimentos de Matemática básica de graduandos nos anos iniciais de Engenharia: desafios, fragilidades e enfrentamentos possíveis
}

\author{
The basic math knowledge of undergraduates in the early years of Engineering: challenges, \\ weaknesses and potential struggles
}

\section{Los conocimientos de Matemática básica de graduandos en los años iniciales de Ingeniería: los desafíos, las fragilidades y los enfrentamientos posibles}

\author{
Lucas Duarte Oliveira ${ }^{1}$ \\ [0000-0001-6228-2021] \\ Tiago Clarimundo Ramos ${ }^{2}$ \\ [0000-0001-5383-7179] \\ Joaquim Carneiro ${ }^{3}$ \\ [0000-0001-9778-5390] \\ Salmon Landi Jr. ${ }^{4}$ \\ [0000-0003-1830-7548]
}

\begin{abstract}
Resumo
Este trabalho tem como principal objetivo analisar o modo como uma turma de 38 estudantes de Engenharia dos anos iniciais responde a problemas elementares de Matemática envolvendo os conteúdos de frações e trigonometria. No momento da pesquisa, todos os participantes cursavam uma disciplina obrigatória da área de Física, numa instituição da Rede Federal de Educação, Ciência e Tecnologia, no Sudoeste de Goiás. Os dados foram obtidos por via da aplicação de um questionário composto de quatro questões abertas. Com base nas análises realizadas, há indícios de que os estudantes, na sua maioria inscritos no $2 \circ$ ou 4 ㅇ período do referido curso, apresentam sérias dificuldades na resolução de problemas matemáticos de nível básico, principalmente nas questões de natureza mais interpretativa. Conclui-se que essa grave realidade educacional constatada na instituição investigada requer o desenvolvimento de medidas urgentes, tais como a ampliação dos projetos de ensino, a adequação do número de estudantes por turma, entre outros investimentos que de algum modo sejam acrescidos aos esforços desenvolvidos pelos professores em contexto de sala de aula visando a mitigação de lacunas formativas básicas destes estudantes.
\end{abstract}

Palavras-chave: Fração. Trigonometria. Aprendizagem. Engenharia. Ensino Superior.

\section{Abstract}

This article has as main objective to analyze how a class of 38-Engineering students from the first years of their study cycle responds to elementary problems in Mathematics involving content of fractions and

${ }^{1}$ duarte-oliveira2010@hotmail.com, Estudante de Engenharia Ambiental, Instituto Federal Goiano, Rio Verde/Goiás/Brasil.

2 tiago.ramos@ifgoiano.edu.br, Doutor em Educação, professor, Instituto Federal Goiano, Rio Verde/Goiás/Brasil.

${ }^{3}$ carneiro@fisica.uminho.pt, Doutor em Engenharia Mecânica, professor, Universidade do Minho, Braga/Portugal.

${ }^{4}$ salmon.landi@ifgoiano.edu.br, Mestre em Física, professor, Instituto Federal Goiano, Rio Verde/Goiás/Brasil. 
trigonometry. At the time of the research, all participants were attending a compulsory curricular unit in the area of Physics at an institution of the Federal Network of Education, Science and Technology, in the Southwest of Goiás. The data was obtained through the application of a questionnaire consisting of four open questions. Based on the analysis, there is some evidence that students, most of them enrolled in the 2nd or 4th term of the course, presents serious difficulties in solving mathematical problems at a basic level of difficulty, mainly in topics of a more interpretative nature. One may conclude that this serious educational reality evidenced in this investigated institution requires the development of urgent actions, such the expansion of teaching projects promoting a suitable adjustment in the number of students per class, among other investments that, in some way, could be added to the teachers' efforts in the classroom context to mitigate these students' basic training gaps.

Keywords: Fraction. Trigonometry. Learning. Engineering. College Education.

\section{Resumen}

Este trabajo trae como principal objetivo analizar la manera como un grupo de 38 estudiantes de Ingeniería de los años iniciales responden a problemas elementales de Matemática, involucrando los contenidos de fracciones y trigonometría. En el momento de la pesquisa, todos los participantes cursaban una disciplina obligatoria del área de Física, en una institución de la Rede Federal de Educação, Ciência e Tecnologia, en el Sudoeste del estado de Goiás. Los datos fueron obtenidos a partir de la aplicación de un cuestionario compuesto de cuatro cuestiones abiertas. Desde los análisis realizados, fueron encontrados indicios de que los estudiantes, inscriptos, en su mayoría, en el segundo o cuarto periodo del referido curso, presentan serias dificultades con la resolución de problemas matemáticos de nivel básico, especialmente en las cuestiones de naturaleza más interpretativa. Así, se concluye que esa grave realidad educacional constatada en la institución investigada requiere el desarrollo de medidas urgentes, tales como la ampliación de los proyectos de enseñanza, la adecuación del número de estudiantes por clase, entre otras inversiones que, de alguna manera, se sumarán a los esfuerzos realizados por los profesores en el contexto del clase para la mitigación de las brechas en la formación básica de estos estudiantes.

Palabras claves: Fracciones. Trigonometría. Aprendizaje. Ingeniería. Enseñanza Superior.

\section{Introdução}

Ler, interpretar e resolver um problema de Matemática requer o domínio de regras e linguagem específicas desta ciência. Com efeito, as regras e a linguagem da Matemática começam por ser habitualmente inseridas no cotidiano de um indivíduo mesmo antes dele frequentar um espaço de educação formal. $\mathrm{O}$ ato de atribuir um símbolo na forma de um número, para cada quantidade de um objeto, ilustra bem este fato. Entretanto, com o passar do tempo, surge naturalmente a necessidade de se conhecer operações gradativamente mais complexas, como ocorre, por exemplo, quando se pretende conferir o troco recebido numa compra, ou mesmo na simples ação de dividir uma goiaba entre duas crianças.

Para Ramos (2017), a Matemática pode ser definida como uma ciência que relaciona o entendimento coerente e crítico com situações encontradas no cotidiano, compreendendo também, uma constante busca pela veracidade dos fatos por meio de um conjunto de técnicas precisas e exatas. Além de ser uma ferramenta imprescindível para as diferentes áreas do conhecimento, enfatizando assim, a sua importância no mundo atual. 
A sociedade de hoje não poderia funcionar sem a Matemática. Virtualmente tudo que agora consideramos como algo absolutamente normal - da televisão aos telefones celulares, de gigantescos jatos de passageiros a sistemas de navegação por satélite em automóveis, de horários de trens a exames médicos por imagem -, tem como base ideias e métodos matemáticos. Às vezes a Matemática tem milhares de anos; outras, foi descoberta na semana passada. A maioria de nós nunca se dá conta de que ela está presente, trabalhando nos bastidores para possibilitar esses milagres da tecnologia moderna. (STEWART, 2014, p. 6).

No contexto escolar, os estudantes têm a possibilidade de desenvolverem diversas competências matemáticas, construindo conhecimento e desenvolvendo capacidades transversais, tais como o raciocínio, a comunicação e a resolução de problemas matemáticos (VISEU et al., 2017). Contudo, no ensino da Matemática são provocados dois sentimentos contraditórios tanto por parte de quem ensina, quanto de quem aprende: no primeiro, a constatação de que se trata de uma área de extrema importância; já no segundo, a insatisfação consequente de resultados negativos obtidos na sua aprendizagem (PACHECO; ANDREIS, 2017). Goulart et al. (2018) afirmam que a Matemática, há muito tempo, ocupa a posição de disciplina com maior grau de dificuldade para muitos estudantes.

Normalmente é possível identificar diferentes obstáculos no ensino da Matemática adstrito aos diferentes níveis de escolaridade, desde o Ensino Fundamental (PACHECO; ANDREIS, 2017) até o Ensino Superior (LOPES; REIS, 2019) - estando, muitas vezes, relacionados com o método tradicional de ensino. Na verdade, o método tradicional de ensino acaba muitas vezes reduzido à mera apresentação de conceitos e exemplos bastante dissociados da realidade. Outro agravante é que, em certa medida, os professores acabam simplesmente por estimular os estudantes a reproduzirem os algoritmos e ideias apresentadas mediante a resolução de exercícios, mas sem desenvolver um pensamento lógico, autônomo e crítico (OLIVEIRA, 2019). De igual modo, até mesmo nos cursos de graduação da área de Ciências Exatas, conforme destacam Lopes e Reis (2019), ainda persiste um método de ensino tradicional.

No Ensino Superior, a insuficiência de conhecimentos matemáticos dificulta sobremodo a aprendizagem, especialmente nas disciplinas iniciais dos cursos superiores de Ciências Exatas e afins. Tais dificuldades chegam a comprometer inclusive a continuidade do estudante no curso, com sérios prejuízos para aquele que necessita concluir a sua formação acadêmica em um prazo máximo estabelecido pela instituição de ensino (MASOLA; ALLEVATO, 2016).

Enfatiza-se que parte dos problemas relacionados com o ensino e aprendizagem da Matemática também estão associados à deficiente formação dos professores da Educação Básica. De acordo com o Censo da Educação Básica, em 2019, nas escolas de Educação Básica localizadas no Sudoeste de Goiás, aproximadamente de 40 a 60\% das disciplinas do ensino médio foram ministradas por professores que não possuíam licenciatura na mesma área da disciplina. (BRASIL, 2020).

Souza et al. (2019) sugerem que, no contexto brasileiro, a formação inicial dos professores apresenta lacunas de natureza tanto teórica quanto prático-pedagógica que necessitam ser sanadas com cursos de formação continuada. Neste mesmo trabalho, os autores alertam, porém, 
para o fato de que a elevada carga de trabalho desencoraja os professores para o seu envolvimento com os encontros formativos e o desenvolvimento de atividades extracurriculares.

Além disso, conforme corroborado por Oliveira (2019), o ensino tradicional não tem conseguido corresponder às atuais exigências de aprendizagem. Com efeito, num mundo marcado pela globalização e constantes mudanças no âmbito tecnológico, tornam-se cada vez mais latentes as vozes que ecoam e pugnam por mudanças a nível educacional, principalmente no ensino da Matemática, a fim de tornar a aprendizagem desta disciplina bem mais perceptível para os estudantes.

Contudo, no ensino de Matemática básica, percebe-se um professor demasiadamente preocupado em apenas cumprir o estabelecido na grade curricular do que instigado em tecer conexões desta ciência com situações da vivência diária dos estudantes (SILVA; SALVI, 2011). Importa também mencionar que

[...] alguns dos programas de aprendizagem de ensino-recepção expositivo nas escolas, mais flagrantemente absurdos e mal concebidos, tenham resultado num inequívoco fracasso dos esforços de aprendizagem dos alunos, com a consequente rejeição destas práticas por muitos professores a favor das novas abordagens de descoberta. Este resultado levou, por sua vez, ao ponto de vista largamente aceite nos círculos educacionais de que a abordagem de ensino expositivo e de aprendizagem por recepção fomenta a aprendizagem de verbalismos vazios (em vez de generalizações), desprovidos de qualquer significado e de compreensão. (AUSUBEL, 2000, p. 7).

De acordo com o nosso ponto de vista, a admissão de estudantes em cursos superiores, mesmo com todas as deficiências em sua formação básica, é resultado de uma política educacional de expansão na oferta de vagas na rede federal de ensino e que, de certa forma, tem contribuído para uma ligeira democratização do Ensino Superior público no Brasil. Os professores que atuam nas Instituições de Ensino Superior, por sua vez, enfrentam sérios problemas, que decorrem da existência de lacunas de conhecimentos básicos de Matemática dos graduandos.

Perante esta problemática, nesta pesquisa, são empreendidos esforços para (i) avaliar aspectos socioculturais de estudantes de um curso de Engenharia, (ii) aferir as dificuldades destes estudantes acerca de conteúdos matemáticos elementares e (iii) propor intervenções que possam contribuir para minimizar os problemas observados.

\section{Metodologia}

Este estudo contempla uma análise qualitativa com particular atenção para o caráter interpretativo dos dados no contexto de sua produção, para além de uma mera quantificação de erros e acertos dos itens avaliados (LIMA; MOREIRA, 2015; SILVA; VANINI, 2019). Para a coleta de dados, inicialmente procedeu-se à elaboração de um questionário composto por questões de natureza sociocultural e questões discursivas sobre conteúdos matemáticos.

O instrumento foi aplicado em uma turma de 38 estudantes de uma das Engenharias oferecidas por um Instituto Federal de Educação, Ciência e Tecnologia localizado no Sudoeste do estado de Goiás. Por uma questão de privacidade, a especificação do curso e da instituição não 
serão reveladas. No momento da pesquisa, conforme apresentado na Tabela 1, todos os discentes que participaram da pesquisa frequentavam a disciplina Física II, do 20 período do referido curso.

Tabela 1 - Número de discentes que participaram da pesquisa por ano de ingresso.

\begin{tabular}{cc}
\hline Ano de ingresso & Número de alunos \\
\hline 2016 & 1 \\
2017 & 1 \\
2018 & 12 \\
2019 & 24 \\
\hline
\end{tabular}

Fonte: elaborado pelos autores a partir do sistema de registro acadêmico.

Embora a maioria dos graduandos envolvidos tenham ingressado no curso em 2019, ou seja, estavam regulares no curso, também havia uma parcela significativa de estudantes de períodos mais avançados, sobretudo do 4 o período, que haviam ingressado em 2018. Optou-se por uma turma de períodos iniciais na consideração de que em quaisquer cursos de Engenharia, geralmente nos primeiros anos, são oferecidas as disciplinas do núcleo básico, as quais requerem um forte apelo aos conhecimentos de Matemática elementar, escopo da presente investigação.

A intervenção junto aos estudantes ocorreu na última semana letiva do 20 semestre do ano de 2019, quando todas as atividades acadêmicas já haviam sido encerradas. Do total de 38 estudantes investigados, 36 haviam concluído a disciplina de Cálculo I (oferecida no 1 período do curso) e 29 inclusive o Cálculo II (oferecida no 2 período com pré-requisito o Cálculo I). A Tabela 2 apresenta os conteúdos programáticos das disciplinas de Cálculo de acordo com o Projeto Pedagógico do curso em questão.

Tabela 2 - Ementas das disciplinas de Cálculo.

\begin{tabular}{cl}
\hline Disciplina & \multicolumn{1}{c}{ Conteúdos Programáticos } \\
\hline Cálculo Diferencial e Integral I & $\begin{array}{l}\text { Funções. Limites de uma função. Derivadas. } \\
\text { Aplicações de Derivadas. Integral. } \\
\text { Aplicações de Integral. }\end{array}$ \\
Cálculo Diferencial e Integral II & $\begin{array}{l}\text { Funçes de mais de uma variável. } \\
\text { Limite de funções de várias variáveis. } \\
\text { Diferenciabilidade de funções de várias variáveis. } \\
\text { Integrais Múltiplas. }\end{array}$ \\
\hline
\end{tabular}

Fonte: elaborado pelos autores a partir do Projeto Pedagógico do curso disponível no site do campus.

Em relação ao questionário, importa realçar que além das questões sobre Matemática básica, também foram elaboradas outras perguntas relacionadas com a vida pessoal do estudante (Quadro 1). 
Quadro 1 - Aspectos do cotidiano extra-acadêmico.

\begin{tabular}{|l|}
\hline Perguntas pessoais \\
\hline Qual foi a rede de ensino onde concluiu o Ensino Médio? \\
\hline Qual é a sua idade? \\
\hline Possui quantos filhos? \\
\hline Trabalhou durante o Ensino Médio? \\
\hline Trabalhou durante o 1ㅇp período do curso que está matriculado? \\
\hline $\begin{array}{l}\text { Em média, estudou quantas horas (fora do horário de aulas) durante o 1o período do curso em que está } \\
\text { matriculado? }\end{array}$ \\
\hline
\end{tabular}

Fonte: elaborado pelos autores.

Tais perguntas foram fundamentais para ampliar a compreensão do contexto de aprendizagem em que os estudantes avaliados estavam inseridos. Até mesmo porque, conforme sublinhado por Tabile e Jacometo (2017), a aprendizagem é um fenômeno complexo que envolve não apenas a cognição, como também fatores emocionais, psicossociais e culturais.

Nesta investigação, foram aplicadas quatro questões de Matemática elementar, as quais são aqui designadas por questão I, questão II, questão III (subdivida nos itens "a", "b", "c" e "d") e questão IV (Quadro 2). Importa ainda acrescentar que as questões I e II foram extraídas de provas aplicadas, anteriormente a esta pesquisa, para estudantes de graduação de outros cursos superiores oferecidos também pela mesma instituição, sendo a constatação de resultados bastante insatisfatórios à motivação principal deste estudo.

Quadro 2 - Questões de Matemática aplicadas aos graduandos do curso de Engenharia.

\begin{abstract}
Questão I
Atualmente, a energia de origem nuclear é a forma de geração de eletricidade, em larga escala, que menos causa impacto ao meio ambiente. Usinas nucleares como as de Angra funcionam em áreas relativamente pequenas, não liberam gases que provocam aquecimento da atmosfera e todos os seus resíduos são mantidos em instalações sob monitoramento permanente. A indústria nuclear surgiu antes do Protocolo de Kyoto, porém com os mesmos princípios de respeito pelo meio ambiente. A Central Nuclear Almirante Álvaro Alberto (CNAAA) conta com duas usinas em operação. A primeira é Angra 1, que entrou em operação comercial em 1985 e tem potência instalada de 640 megawatts. A outra é Angra 2, que começou a operar em 2001 e cuja potência é de 1.350 megawatts. Para os próximos anos, está prevista a entrada em operação de Angra 3, de 1.405 megawatts, que está com as obras a decorrerem em pleno vapor. As usinas nucleares dão uma importante contribuição para a matriz elétrica brasileira. Conjuntamente, geram o equivalente a um terço do consumo de energia elétrica do estado do Rio de Janeiro. Além disso, as substâncias radioativas de baixa e média radioatividade, resultantes da geração de energia nuclear pelas usinas de Angra, são armazenadas adequadamente em instalações da própria CNAAA, em Itaorna. Nessas categorias inserem-se os materiais de limpeza, peças de reposição, roupas, sapatilhas e luvas utilizadas no interior dos edifícios dos reatores, impurezas, filtros, dentre outros. Por outro lado, as substâncias de alta radioatividade, como o próprio combustível nuclear usado nos reatores, ficam armazenadas dentro das usinas. Entretanto, este material poderá ser reaproveitado, como já acontece em outros países. Disponível em: <http://www.eletronuclear.gov.br/Aempresa.aspx>. Acesso em: 26/06/2018 (adaptado).
\end{abstract}

A partir destas informações, determine, em megawatts, a potência elétrica atual instalada do estado do Rio de Janeiro.

(Elaborada pelo autor SLJ como parte de uma questão de uma prova de Física aplicada para a turma do 10 período do curso de Ciências Biológicas do ano de 2018.) 


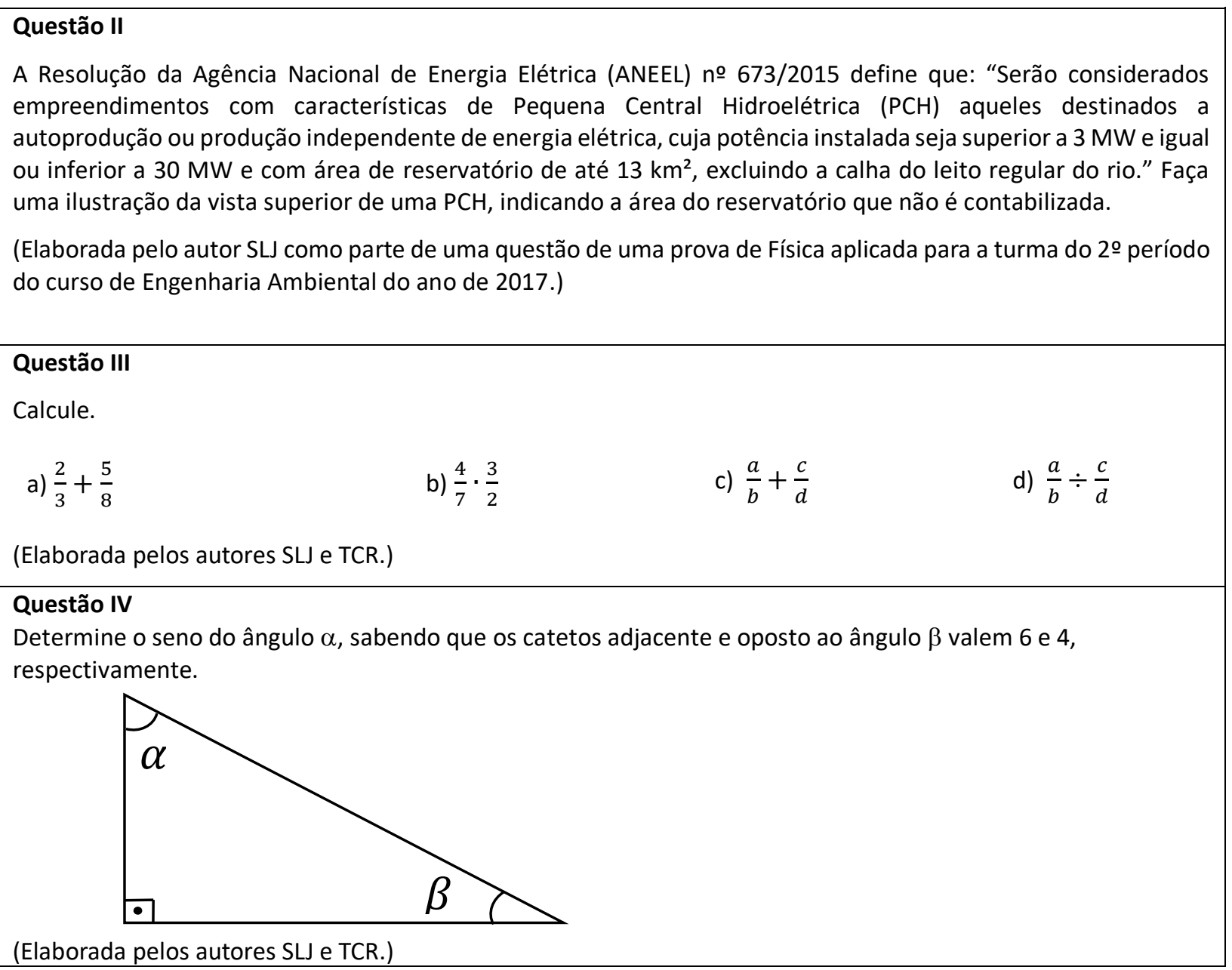

\section{Resultados e discussões}

\subsection{Traços de realidade e perfil dos estudantes}

Das análises das respostas ao questionário (Tabela 3), constatou-se que alguns fatores parecem interferir ou influenciar negativamente na aprendizagem dos estudantes. A rede em que o estudante completou o Ensino Médio é maioritariamente pública; quase metade do grupo pesquisado participava de atividades laborais; além disso, no 10 período do curso, muitos não tinham dedicação extraclasse de pelo menos duas a três horas por dia.

Tabela 3 - Resultados das perguntas de cunho pessoal.

\begin{tabular}{lcc}
\hline \multicolumn{1}{c}{ Respostas aos itens do questionário } & Número de estudantes & Parcela dos estudantes (\%) \\
Concluiu o Ensino Médio na rede estadual & 27 & 71 \\
Faixa etária dos 18 aos 21 anos & 31 & 82 \\
Não possui filho(s) & 38 & 100 \\
Não trabalhou durante o Ensino Médio & 22 & 58 \\
Não trabalhou durante o 10 período da graduação & 24 & 63 \\
\hline
\end{tabular}


Fonte: elaborado pelos autores.

Acrescenta-se que, dentre os 11 indivíduos que concluíram o Ensino Médio na rede particular, apenas um alegou ter trabalhado durante esta fase de escolaridade. Por outro lado, dentre os 27 oriundos da rede pública, 15 afirmaram terem trabalhado concomitantemente aos seus estudos de nível médio. Perante estes resultados, constata-se que para muitos jovens, estudar e trabalhar tem-se afigurado como uma imposição e não uma escolha. Cada um com as suas necessidades e quiçá dos seus problemas, recorrentemente acabam por justificar tal prática. Entretanto, segundo Oliveira (2019), caso esses jovens tivessem tido a possibilidade de prolongar seu processo de escolarização, as repercussões em seu futuro profissional certamente poderiam ser bastante melhores.

Desde o Ensino Médio, em nosso entendimento, o trabalho coexistente com os estudos é um fator que pode comprometer o aproveitamento escolar dos jovens de diferentes maneiras, sejam através de reações de sobrecarga físicas, psicológicas e/ou emocionais. Por isso, há evidências de que muitos jovens acabam por negligenciar os seus estudos, afetando negativamente o seu êxito e futuro acadêmico e profissional.

De acordo com Tartuce et al. (2018), o Ensino Médio é caracterizado por ser uma etapa crucial na formação dos indivíduos, até mesmo pelas múltiplas funções que assume de consolidação dos conhecimentos e competências básicas dos estudantes, preparação para o Ensino Superior e/ou mercado de trabalho e formação de cidadãos. Não obstante, a oferta de uma boa formação aos jovens é essencial, sobretudo para assegurar que tenham condições de prosseguirem, de modo satisfatório, os seus estudos no Ensino Superior.

De igual modo, a dedicação de um período extraclasse, conforme defendem Santos, Galvanin e Carvalho (2017), tem como fundamento principal contribuir com a complementação e o aprofundamento dos conteúdos ministrados pelos professores em contexto de sala de aula. Entretanto, como verificado neste estudo (Tabela 3), alguns estudantes têm utilizado o referido período para fins laborais, com possíveis prejuízos no âmbito do seu rendimento escolar.

De um modo geral, no Ensino Básico ofertado pela rede pública, são encontrados problemas das mais variadas tipologias, como a falta de professores, a indisciplina e a agressividade dos alunos e o abandono do ensino (OLIVEIRA; MELO-SILVA, 2010). As lacunas de conhecimento, contudo, só se tornam mais perceptíveis principalmente quando estes sujeitos ingressam no Ensino Superior. Lopes e Reis (2019) acrescentam que o ingresso no Ensino Superior é bastante estressante para os jovens. Além das suas dificuldades na aprendizagem dos novos conceitos, a exposição à manipulação de representações de novos símbolos, mormente como são exigidas nos cursos de graduação da área das Ciências Exatas, levam muitos deles a optarem pela desistência do curso.

Assim sendo, verifica-se que o desempenho acadêmico é um fenômeno complexo que exige uma análise multivariada, levando em consideração fatores pessoais, sóciodemográficos, pedagógicos e institucionais, que são aspectos que impactam diretamente sobre o rendimento do estudante (ROCHA; LELES; QUEIROZ, 2018). Deste modo, a análise conjunta destes fatores é fundamental para a compreensão das problemáticas que afligem os estudantes no Ensino Superior. 


\subsection{Análises do nível de compreensão dos estudantes acerca dos conteúdos elementares de Matemática}

Destaca-se que o desempenho dos estudantes que ingressaram em 2019 foi semelhante ao dos ingressos em anos anteriores. Por este motivo, optou-se em não segmentar as análises das respostas destes dois grupos.

Das análises das respostas à questão I, embora o cálculo a ser realizado seja relativamente simples, isto é: " $(640+1350) \times 3$ ", apenas cerca de $29 \%$ dos estudantes o fizeram corretamente. Dentre os 11 sujeitos que obtiveram êxito, apenas dois afirmaram ter trabalhado durante o Ensino Médio. Acrescenta-se ainda que os erros mais comuns constituem em apresentar o resultado a partir das seguintes expressões: “ $(640+1350) \div 3$ " ou " $(640+$ $1350+1405) \times 3$ "; sugerindo que os estudantes apresentaram uma certa dificuldade em interpretar corretamente o enunciado da questão. Cavasotto e Viali (2011) num trabalho investigativo com estudantes de Engenharia de duas turmas de Cálculo de uma universidade da rede privada de Porto Alegre-RS também constataram dificuldades dos participantes face à interpretação dos enunciados das questões propostas.

A Fig. 1 mostra o tipo de erro mais comum cometido pelos estudantes ao responderem a questão I. Neste caso, observa-se que os mesmos não se aperceberam para o fato de que o valor apresentado (cerca de $663 \mathrm{MW}$ ) para a potência instalada de todo o estado é inferior à potência instalada em Angra 2. O que significa que esta unidade sozinha conseguiria suprir a demanda de energia do estado do Rio de Janeiro, o que pela lógica está em desacordo com o enunciado da questão. Neste sentido, é importante reforçar a necessidade "de os alunos serem conduzidos a desenvolver suas capacidades de leitura em Matemática e de expressão do próprio raciocínio que os levam à compreensão e utilização dos resultados matemáticos” (MALTA, 2004).

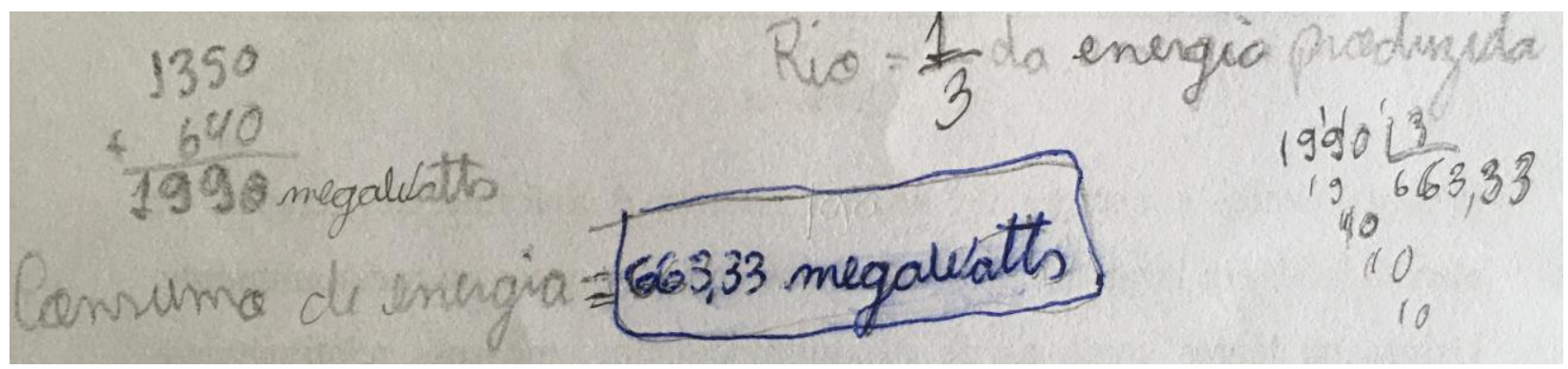

Figura 1 - Erro mais comum apresentado para a questão I.

Fonte: questionários

Surpreendentemente, dos 38 participantes deste estudo, apenas um respondeu a questão Il de maneira satisfatória. Esta questão exige do estudante uma compreensão da fração como parte-todo, em que a parte (calha do leito regular do rio) não é contabilizada na área do reservatório (todo), pois aquela já existia antes mesmo da construção da barragem da hidroelétrica. Interessa destacar que Monteiro e Groenwald (2014) também reportaram a dificuldade em reconhecer a relação parte-todo, principalmente na forma contínua, num estudo realizado com estudantes do 7ํano de uma escola municipal localizada na cidade de Canoas-RS. 
Em nossa pesquisa, é curioso o fato de muitos estudantes terem interpretado a expressão "calha do leito regular do rio" como se o rio estivesse localizado na extremidade do reservatório, como uma calha em torno de um telhado (Fig. 2).

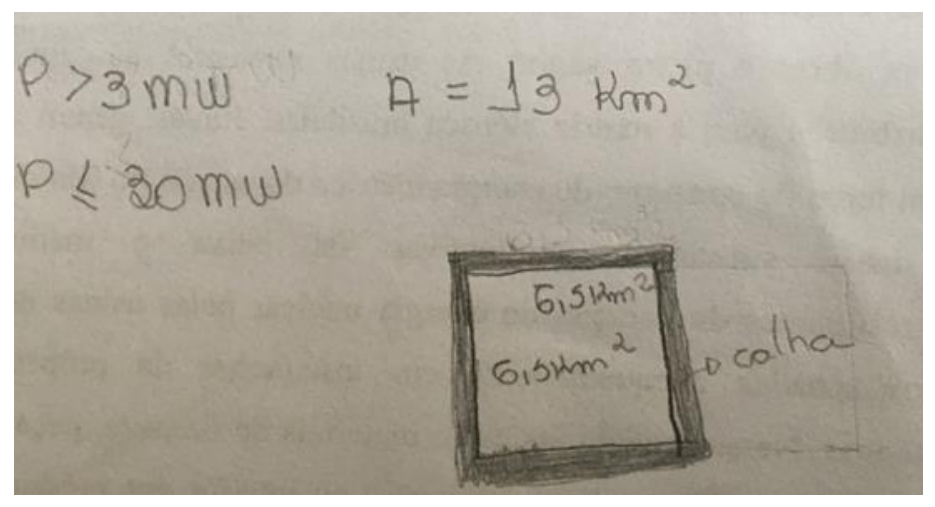

Figura 2 - Erro típico apresentado para a questão II.

Fonte: questionários.

A questão III exigiu apenas o conhecimento da linguagem e de regras específicas da Matemática. Neste caso, os estudantes tiveram melhor desempenho do que quando comparado com as questões anteriores. As percentagens de respostas corretas em cada um destes quatro itens foram, respectivamente, $87 \%, 87 \%, 68 \%$ e $89 \%$. Observou-se que dentre os 11 estudantes que concluíram o Ensino Médio na rede particular, apenas um indivíduo não acertou todos os itens da questão III. Por outro lado, somente cinco dos estudantes que concluíram os seus estudos na rede pública responderam corretamente todos os itens desta questão. Importa mencionar que, em geral, no âmbito do sistema educacional brasileiro, quando comparadas às escolas privadas, as escolas públicas das redes municipal e estadual, apresentam estrutura e qualidade de ensino inferiores e com poucos docentes licenciados na área de atuação (DUTRA-THOMÉ; PEREIRA; KOLLER, 2016).

De qualquer modo, é preocupante o fato de que ainda assim $13 \%$ dos estudantes não responderam corretamente a uma simples soma de frações, como proposto no item "a". Além disso, nota-se que mantendo a mesma operação, mas substituindo os números, item "a", por letras, item " $c$ ", a percentagem de erro aumentou para 32\%. Este significativo crescimento revela que muitos estudantes apresentam também deficiências com problemas literais básicos. Neste ponto, é importante refletir sobre Lopes (1999, p. 125):

[...] Se você não sabe dividir, não vai saber o que é uma taxa, se você não sabe o que é uma taxa não vai saber o que é uma derivada e assim por diante. Esta é talvez uma das principais razões porque existem tantas reprovações em Cálculo em nossas universidades. Em muitos casos, os estudantes universitários não sabem os conceitos matemáticos anteriores que são necessários para fazer os cursos de Cálculo. 
Neste mesmo trabalho, o autor (à época professor na Universidade Federal do Rio Grande do Sul) ainda pontua que: "É procedente informar ao leitor que alguns estudantes matriculados nos cursos de Cálculo não sabem somar frações!!". Palhares et al. (2009) alertam que a Matemática elementar representa uma estrutura pedagogicamente complexa que dificilmente pode ser classificada como simples ensinar e que no processo de aprendizagem da Matemática cada estágio é fortemente dependente do anterior.

Perante os resultados obtidos, enfatiza-se a natureza do erro mais comum cometido no item "a": soma dos numeradores dividido pela soma dos denominadores, como exemplificado na Fig. 3. Este mesmo erro foi observado em pesquisa recente com estudantes do Ensino Fundamental e Médio de uma escola estadual localizada no município de Itabaiana-SE e também com graduandos de um curso de licenciatura em Matemática (ETCHEVERRIA et al., 2019). Os autores deste trabalho destacam que estes erros mostram a falta de compreensão nos processos operatórios, de maneira que os estudantes aplicam regras memorizadas sem refletirem sobre a sua validade.

a) $\frac{2}{3}+\frac{5}{8}$

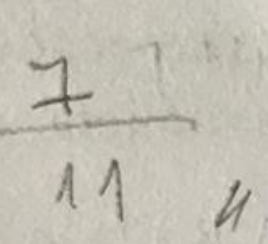

Figura 3 - Erro mais comum para o item "a" da questão III. Fonte: questionários.

Infelizmente, a aprendizagem dos números fracionários tem um histórico desagradável para estudantes e professores. Este fato frequentemente decorre de uma elevada dificuldade na compreensão da fração como um valor numérico, muitas vezes considerada como meros símbolos (ETCHEVERRIA et al., 2019). Silva e Aquino (2019) destacam que o ensino deste conteúdo ocorre, muitas vezes, mediante a apresentação de regras e fórmulas sem a real compreensão do significado de um número fracionário.

Observa-se, contudo, algumas experiências interessantes, como a de Figueiredo, Moura e Araújo (2018), que utilizaram diferentes jogos de aprendizagem, muitos deles confeccionados pelos próprios estudantes do 7ํano de uma escola pública, para o ensino do conteúdo de frações. Os autores salientaram que nesta proposta metodológica, o discente é estimulado a trabalhar pela cooperação e não pela coação. No trabalho, foi verificado que a aplicação de jogos de aprendizagem torna-se mais eficiente através de um período mais longo de utilização, sendo imprescindível um bom planejamento e a orientação do docente durante o desenvolvimento das atividades.

Por outro lado, Führ (2019) argumenta que a história da Matemática pode ser uma grande aliada no ensino de conteúdos matemáticos. No caso específico das frações, a autora relata a sua importância em problemas práticos que remontam ao período do antigo Egito (envolvendo a necessidade de se calcular frações de áreas para o pagamento de impostos durante as cheias do rio Nilo) e também em documentos dos antigos romanos (relacionados com o particionamento 
de unidades de medidas utilizadas no comércio) e que o resgaste destas situações pode colaborar com o ensino e aprendizagem deste tema. Sobretudo porque problemas de natureza prática podem instigar a curiosidade dos discentes, colaborando para o aprofundamento de seus conhecimentos.

Por fim, a questão IV envolve um problema típico de trigonometria, em que os conceitos envolvidos são importantes, por exemplo, na resolução de integrais pela técnica conhecida por substituição trigonométrica. Acrescenta-se que este método de integração é frequentemente aplicado na resolução de problemas em Física, especificamente na mecânica, quando se considera o movimento de queda livre de um corpo sob uma força de resistência do ar proporcional ao quadrado da velocidade do movimento (DA SILVA; FUMIÃ, 2019) e também no eletromagnetismo no que se refere, por exemplo, ao cálculo do campo elétrico produzido por uma barra isolante carregada uniformemente (NUSSENZVEIG, 2015).

Embora a maioria (55\%) dos estudantes tenham acertado a questão IV, entende-se que esta percentagem ainda está muito longe de ser a ideal. Além disso, verificou-se que alguns erros cometidos são preocupantes: afirmar que o produto dos catetos equivale ao ângulo $\alpha$ ou ainda aplicar o teorema de Pitágoras de maneira equivocada (Fig. 4). Conforme relatado por Dionizio e Brandt (2011), estudantes da 2a série do Ensino Médio de uma escola pública de Ponta GrossaPR também apresentaram dificuldades em compreender conceitos básicos de trigonometria devido, muitas vezes, à falta de contextualização, sendo comum a apresentação dos conceitos de forma muito abstrata. Esta constatação reforça a necessidade de melhorias das práticas pedagógicas dos professores, sobretudo, quando forem apresentar novos conceitos aos estudantes.
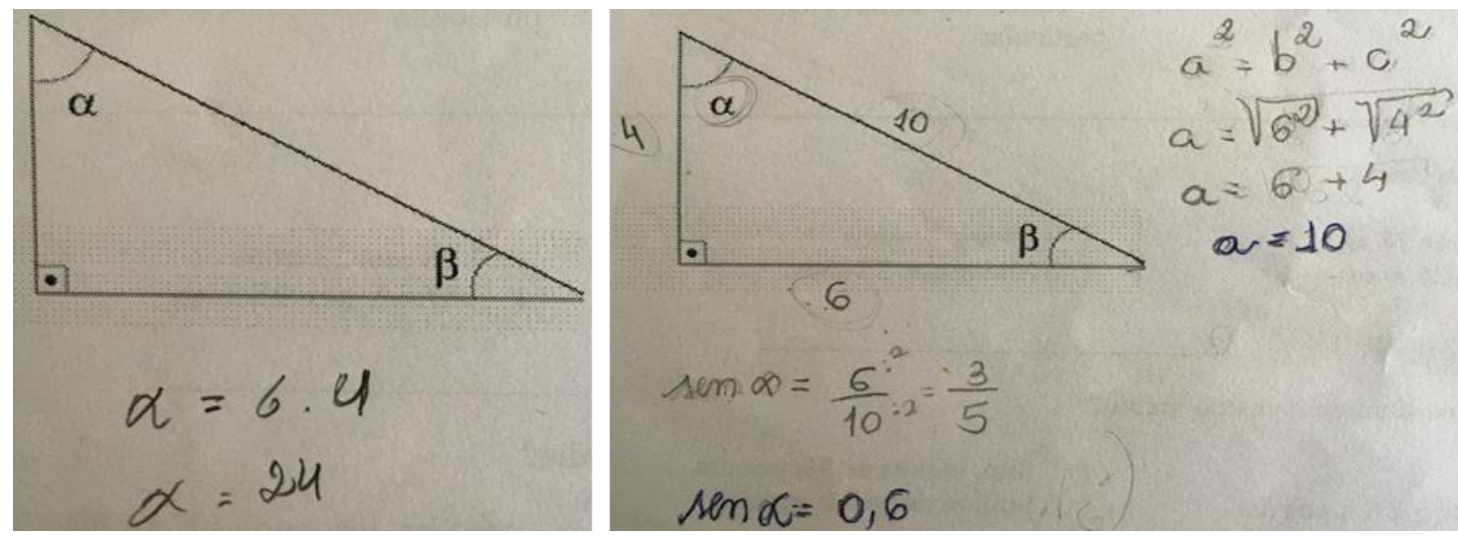

Figura 4 - Erros preocupantes apresentados para a questão IV.

Fonte: questionários

Oliveira e Fernandes (2010) demonstraram resultados muito satisfatórios no ensino introdutório das funções seno e cosseno para estudantes da 2 a série do Ensino Médio de uma escola pública da cidade de Guaratinguetá-SP. Nesta pesquisa, os autores utilizaram tanto instrumentos "tradicionais" no ensino da trigonometria (lápis, papel, régua e transferidor) quanto 
elementos relativos às tecnologias digitais, por meio do software GeoGebra ${ }^{5}$. Além disso, os pesquisadores consideraram os erros observados durante as atividades propostas com os instrumentos "tradicionais" como forma de reconhecer as concepções já consolidadas na estrutura cognitiva dos estudantes. Desta forma, o erro foi visto como recurso à aprendizagem, pois foi utilizado como o ponto de partida para o planejamento das atividades com o computador. Em depoimentos, registrados por meio de gravações, os estudantes concordaram que a inserção do software contribuiu de forma muito positiva para superação das dificuldades inicialmente constatadas. Os resultados revelaram, portanto, que a aplicação de uma estratégia pedagógica sustentada por tecnologias diversas pode resultar em avanços na compreensão sobre o tema em estudo.

Silva e Salvi (2011) também relataram bons resultados com estudantes da 3a série do Ensino Médio que cursavam dependência em Matemática mediante a apresentação do ciclo trigonométrico de forma lúdica e menos formal por meio de um jogo: a mandala trigonométrica. Os autores observaram que quando há um comprometimento por parte de estudantes e professor com a prática do jogo, o lúdico apresenta-se como uma excelente alternativa pedagógica, sobretudo, porque (i) num ambiente descontraído, o estudante é encorajado a expor e dirimir suas dúvidas, com a vantagem de o processo poder se repetir por inúmeras vezes, (ii) favorece o relacionamento interpessoal, estimulando a aprendizagem solidária e (iii) possibilita ao professor agir como um investigador no processo de reelaboração dos conhecimentos junto com os seus estudantes.

Gomes (2013), por sua vez, propôs uma relevante discussão envolvendo a utilização da história da Matemática como fio condutor para o desenvolvimento de uma sequência de atividades para o ensino de trigonometria. O produto educacional produzido, um fascículo com 32 páginas, foi aplicado em forma de oficinas pedagógicas envolvendo um grupo de professores de Matemática de escolas públicas da cidade de Natal-RN. O autor destaca que os participantes encontraram algumas dificuldades durante o desenvolvimento das atividades e enfatiza a necessidade de uma preparação prévia dos professores a fim de se obter uma maior eficácia com a proposta de ensino. Especificamente, os requisitos elencados vão desde o domínio de conhecimentos em geometria, de cálculos algébricos inclusive com números irracionais até à familiarização com construções geométricas e com o estudo das funções.

Ao longo dos últimos anos, a articulação do ensino da Matemática com a história (GOMES; 2013; FÜHR, 2019), a adoção de objetos tecnológicos de aprendizagem (OLIVEIRA; FERNANDES, 2010; SILVA; VANINI, 2019) e/ou mesmo a exploração de jogos didáticos (SILVA; SALVI, 2011; FIGUEIREDO; MOURA; ARAÚJO, 2018) tem se apontado como recursos bastante profícuos ao processo de ensino-aprendizagem em escolas brasileiras. Em nosso entendimento, contudo, é importante que as possíveis estratégias de enfrentamento das dificuldades de aprendizagem tenham sempre um design que contemple a problematização e ressignificação dos conteúdos para os estudantes no contexto de suas respectivas realidades

A Tabela 4 apresenta o número de estudantes assim como as percentagens de acertos e erros para cada uma das questões aplicadas. De forma geral, constata-se que o desempenho dos estudantes foi manifestamente pior para as questões que necessitam de alguma interpretação

\footnotetext{
${ }^{5}$ Pode ser adquirido gratuitamente em <https://www.geogebra.org/>.
} 
(questões I e II) em comparação com outras que exigem sobretudo conhecimentos mais técnicos (questões III e IV). Considerando-se o teor das questões e o fato de que o público alvo eram estudantes de um curso de Engenharia do 2 o período ou de períodos ainda mais avançados, os resultados obtidos com a aplicação do questionário e resumidos na Tabela 4 mostram-se bastante insatisfatórios.

Tabela 4 - Número de estudantes $(N)$ e percentuais $(P)$ de acertos e erros para cada uma das questões do questionário apresentado no Quadro 2.

\begin{tabular}{lcccccccc} 
& Questão I & Questão II & \multicolumn{4}{c}{ Questão III } & Questão IV \\
\cline { 4 - 8 } & & & a & b & C & D \\
\hline Acertos: N | P & $11 \mid 29 \%$ & $1 \mid 3 \%$ & $33 \mid 87 \%$ & $33 \mid 87 \%$ & $26 \mid 68 \%$ & $34 \mid 89 \%$ & $21 \mid 55 \%$ \\
Erros: N | P & $27 \mid 71 \%$ & $37 \mid 97 \%$ & $5 \mid 13 \%$ & $5 \mid 13 \%$ & $12 \mid 32 \%$ & $4 \mid 11 \%$ & $17 \mid 45 \%$ \\
\hline
\end{tabular}

Fonte: elaborado pelos autores a partir dos resultados obtidos.

Realça-se ainda que dentre os 38 participantes, apenas cinco indivíduos responderam corretamente às questões I, III e IV, entre os quais somente um deles declarou ter trabalhado durante o 10 período da graduação. Além disso, sete dos oito estudantes que afirmaram ter estudado $4 \mathrm{~h}$ ou mais por dia durante o 1 o período do curso cometeram algum erro nas questões I ou III, sugerindo que a maioria destes estudantes admitem ter uma certa fragilidade no que concerne aos seus conhecimentos básicos e que ainda não foi superada.

Atendendo aos resultados aqui relatados, torna-se urgente que a instituição encete um conjunto de ações específicas a fim de enfrentar os problemas que incidem sobre os seus estudantes e professores. Neste sentido, na próxima seção, propôs-se um conjunto de ações que visa a consecução de melhorias no processo de ensino-aprendizagem dos seus estudantes.

\subsection{Recomendações que podem contribuir para superar os desafios}

Perante o exposto, é imprescindível promoverem-se ações com os estudantes logo no 10 período do curso com o intuito de diminuir o déficit de conhecimentos necessários para assegurar um bom rendimento ao longo dos períodos subsequentes. Enfatiza-se ainda a necessidade, sobretudo, de programas permanentes, com o uso de ferramentas do ensino a distância, que possam de fato corrigir algumas lacunas na formação básica dos discentes. Além disso, também é importante a promoção e implementação de ações que ajudem a colmatar eventuais lacunas de natureza pedagógica dos docentes, inclusive com o intuito de aproveitar melhor as tecnologias digitais de ensino disponíveis atualmente. É neste sentido que são apresentadas em seguida algumas medidas que podem contribuir para a obtenção de melhorias no processo de ensinoaprendizagem, nomeadamente: 
i. utilização do material disponibilizado pela Khan Academy, atentando-se especialmente para as recomendações de Gray e Lindstrøn (2019);

ii. elaboração de salas em ambiente virtual dirigidas para o ensino de temas da Matemática considerados fundamentais para as disciplinas básicas de cada curso. Além disso, é fortemente desejável que se adote o ensino numa perspectiva investigativa como discutido por Silva Júnior e Coelho (2020);

iii. capacitação pedagógica dos professores, a fim de conseguirem aperfeiçoar as suas práticas de ensino e métodos de avaliação como bem sinalizaram Moraes et al. (2020);

iv. desenvolvimento de um material acessível remotamente, por professores de diferentes áreas científicas atuando conjuntamente, em que situações-problema relacionadas com a área de formação dos acadêmicos sejam utilizadas como ponto de partida para a discussão de conteúdos matemáticos, conforme referido por Gois, Silva e Dalto (2019) e

v. redução do número de vagas oferecidas nos cursos de Engenharia.

Por se tratar de uma característica muito peculiar, o item " $v$ " merece aqui uma análise mais detalhada. Em primeiro lugar, é necessário esclarecer que é consensual, entre os autores do presente trabalho, que o número de vagas disponibilizadas anualmente (50) para o ingresso nos cursos superiores oferecidos no âmbito do campus em que decorreu esta pesquisa compromete negativamente a qualidade do trabalho docente. Este fato é agravado quando se trata de cursos de Engenharia, sobretudo quando, como sugerido pelos resultados apresentados na seção anterior, muitos dos graduandos provavelmente ainda não estejam suficientemente preparados para o Ensino Superior.

Para fins de comparação, em pesquisa realizada nos respectivos sites de outros campi da mesma rede federal e também localizados em Goiás, constatou-se existirem números de vagas bem mais modestos, tais como 40 ou 36 vagas, porém uma expressiva maioria reserva apenas 30 vagas para os cursos de Engenharia. Diante do exposto, depreende-se que seria importante que a direção, conjuntamente com os seus pares, rediscutisse os critérios e a política de vagas implementada no campus. Em nosso entendimento, uma redução para 30 (o número ideal perante a realidade constatada) ou até mesmo 36 vagas, poderia favorecer o uso de estratégias de ensino que valorizem a atividade dos estudantes, em detrimento de práticas individualizadas e de assimilação passiva do conhecimento (VISEU; ROCHA, 2018).

Pontua-se ainda a contribuição de Gatti (2014, p. 49), em que no contexto do presente trabalho, o termo "licenciandos" pode ser perfeitamente substituído por "graduandos":

[...] é importante ter bons planejamentos curriculares e didáticos, com a criação de estímulos culturais e aproveitamento da motivação que esses segmentos portam. Para tanto, porém, é necessário não só um envolvimento pedagógico adequado com os licenciandos como também um projeto institucional para o acolhimento e formação desses alunos.

Por fim, em sintonia com as ideias de Malta (2004), defende-se veementemente a utilização efetiva de um material didático que promova um acesso direto do acadêmico ao conteúdo a ser aprendido. A autora enfatiza que o professor de Matemática universitário não deve substituir o material didático, mas auxiliar os estudantes ao "aprender a ler matemática" e 
também afirma que as deficiências com a utilização da linguagem escrita estão intimamente relacionadas com as dificuldades de compreensão da Matemática, por isso: "sem o desenvolvimento do domínio da linguagem necessária à apreensão de conceitos abstratos nos seus diversos níveis, não pode haver o desenvolvimento do pensamento matemático."

\section{Considerações finais}

No que concerne aos dados referentes ao cotidiano extra-acadêmico, destaca-se que $71 \%$ concluíram o Ensino Médio na rede estadual, 82\% possuem entre 18 e 21 anos, nenhum dos estudantes tem filhos, $57 \%$ não trabalharam durante o Ensino Médio, $63 \%$ não trabalharam durante o 1 - período do curso e $53 \%$ estudaram, em média, uma hora por dia durante o 1 은 período da graduação. Exceto este último dado, em geral, as percentagens observadas poderiam sugerir respostas mais satisfatórias em relação às questões propostas no questionário aplicado.

Observa-se que apesar da simplicidade do cálculo a ser executado na questão I, $71 \%$ dos estudantes não alcançaram êxito em sua resolução, sugerindo uma certa dificuldade em interpretar o problema. Esta hipótese também pode ser o motivo que levou 37 indivíduos (de um total de 38) a não responderem corretamente à questão II. Além disso, é preocupante a constatação de que $32 \%$ dos participantes não resolveram corretamente uma soma de frações com letras e que $45 \%$ demonstraram conhecimentos insuficientes acerca de trigonometria no triângulo retângulo. Estes números revelam uma certa discrepância tendo em conta que cerca de 95\% dos estudantes que participaram deste estudo foram aprovados na disciplina Cálculo Diferencial e Integral I e 76\% aprovados inclusive em Cálculo Diferencial e Integral II. Estes resultados são também preocupantes, já que $63 \%$ dos participantes eram estudantes do 20 período de um curso superior em Engenharia e os outros de períodos ainda mais avançados.

Constata-se que o problema da falta de conhecimentos básicos de estudantes que ingressam no Ensino Superior no Brasil não está restrito ao local de aplicação desta pesquisa, nem tampouco é recente. Pelo contrário, observa-se que esta questão está presente em diversas localidades do território nacional, evidenciando um certo desinteresse dos órgãos públicos em relação à educação destes jovens. Neste sentido, sugere-se à direção do campus investigado nesta pesquisa um posicionamento no que se refere ao desenvolvimento de ações, tais como as elencadas na seção anterior, que propõem melhorias na formação básica de discentes, assim como o aperfeiçoamento na formação pedagógica dos docentes. Caso contrário, em nosso entendimento, qualquer atitude de omissão face às demandas observadas certamente contribuirá para acentuar ainda mais os insucessos, desistências e frustrações no curso de Engenharia analisado no âmbito desta pesquisa.

\section{Referências}

AUSUBEL, David P. Aquisição e retenção de conhecimentos: uma perspectiva cognitiva. 1. ed. New York: Plátano Edições Técnicas, 2000.

Brasil. Instituto Nacional de Estudos e Pesquisas Educacionais Anísio Teixeira (Inep). Censo da Educação Básica 2019: resumo Técnico. Brasília, 2020. 
CAVASOTTO, Marcelo; VIALI, Lori. Dificuldades na aprendizagem de cálculo: o que os erros podem informar. Boletim GEPEM, n. 59, p. 15-33, 2011.

DIONIZIO, Fátima Q.; BRANDT, Célia Finck. Análise das dificuldades apresentadas pelos alunos do ensino médio em trigonometria. In: CONGRESSO NACIONAL DE EDUCAÇÃO - EDUCERE, 10., 2011, Curitiba. Anais... Curitiba: PUCPR, 2011. p. $4408-4421$.

DUTRA-THOME, Luciana; PEREIRA, Anderson Siqueira; KOLLER, Silvia Helena. O Desafio de Conciliar Trabalho e Escola: Características Sociodemográficas de Jovens Trabalhadores e Não-trabalhadores. Psicologia: Teoria e Pesquisa, v. 32, n. 1, p. 101-109, 2016.

ETCHEVERRIA, Teresa Cristina et al. Reflexões acerca do desempenho e das dificuldades de estudantes da educação básica e superior nas operações com frações. Revista Sergipana de Matemática e Educação Matemática, n. 2, p. 71-88, 2019.

FIGUEIREDO, Jairo V. de; MOURA, Egnilson M. de; ARAÚJO, Joniel Mendes de. O ensino de frações mediado por jogos de aprendizagem: uma proposta para o ensino. Revista da Rede Amazônica de Educação em Ciências e Matemática, v. 6, n. 2, p. 259-272, 2018.

FÜHR, Luciane. A história da Matemática como facilitadora para o ensino e aprendizagem de frações. Revista Sergipana de Matemática e Educação Matemática, n. 1, p. 52-67, 2019.

GATTI, Bernardete A. Formação inicial de professores para a educação básica: pesquisas e políticas educacionais. Estudos em Avaliação Educacional, v. 25, n. 57, p. 24-54, 2014.

GOIS, Victor Hugo S.; SILVA, Karina Alessandra P. da; DALTO, Jader Otavio. Análise da Produção Escrita de Estudantes do Ensino Superior: Uma Abordagem Semiótica. Revista de Educação em Ciência e Tecnologia, v. 12 , n. 2, p. $255-278,2019$.

GOMES, Maria Laura M. História do Ensino da Matemática: uma introdução. Belo Horizonte: CAED-UFMG, 2013.

GOULART, Ana Teresa et al. Dificuldades no aprendizado de Matemática: percepção de estudantes de duas escolas públicas de Anita Garibaldi. Revista Cientefico, v. 18, n. 37, p. 47-73. 2018.

GRAY, James; LINDSTR ØM, Christine. Five Tips for Integrating Khan Academy in Your Course. Physics Teacher, v. 57, p. 406-408, 2019.

LIMA, Maria S. B.; MOREIRA, Érika Vanessa. Pesquisa qualitativa em geografia. Caderno Prudentino de Geografia, n. 37, v. 2, p. 27-55, 2015.

LOPES, Artur. Algumas reflexões sobre a questão do alto índice de reprovação nos cursos de Cálculo da UFRGS. Sociedade Brasileira de Matemática, n. 26/27, p. 123-146, 1999.

LOPES, Aldo P. C.; REIS, Frederico S. Vamos viajar? - Uma abordagem da aprendizagem baseada em problemas no cálculo diferencial e integral com alunos de Engenharia. Revista de Educação Matemática, v. 16, n. 23, p. 449-469, 2019. 
MALTA, laci. Linguagem, leitura e Matemática. In CURY, Helena N. Disciplinas Matemáticas em cursos superiores: reflexões, relatos, propostas. Porto Alegre: EDIPUCRS, 2004. p. 41-62.

MASOLA, Wilson J.; ALLEVATO, Norma Suely G. Dificuldades de aprendizagem Matemática de alunos ingressantes na educação superior. Revista Brasileira de Ensino Superior, v. 2, n. 1, p. 64-74, 2016.

MONTEIRO, Alexandre B.; GROENWALD, Cláudia Lisete O. Dificuldades na Aprendizagem de Frações: Reflexões a partir de uma Experiência Utilizando Testes Adaptativos. Revista de Educação em Ciência e Tecnologia, v. 7, n. 2, p. 103-135, 2014.

MORAES, Mônica et al. A evasão em cursos de licenciatura em um instituto federal. Brazilian Journal of Development, v. 6, n. 3, p. p. $12059-12074,2020$.

NUSSENZVEIG, Herch M. Curso de Física Básica: Eletromagnetismo. 2. ed. São Paulo: Edgard Blücher, 2015.

OLIVEIRA, Gerson P. de; FERNANDES, Ricardo U. Uso de tecnologias para ensino de trigonometria: estratégias pedagógicas para a construção significativa da aprendizagem. Educação Matemática Pesquisa, v. 12, n. 3, p. 548-577, 2010.

OLIVEIRA, Marcelo S. Uma reflexão sobre a ideia de superação do ensino tradicional na educação Matemática: a dicotomia entre a abordagem clássica e abordagens inovadoras em foco. Boletim online de Educação Matemática, v. 7, n. 14, p. 79-93, 2019.

OLIVEIRA, Melina D. de; MELO-SILVA, Lucy L. Estudantes universitários: a influência das variáveis socioeconômicas e culturais na carreira. Revista Semestral da Associação Brasileira de Psicologia Escolar e Educacional, v. 14, n. 1, p. 23-34, 2010.

PACHECO, Marina B.; ANDREIS, Greice S. L. Causas das dificuldades de aprendizagem em Matemática: percepção de professores e estudantes do 3 o ano do Ensino Médio. Revista Principia, n. 18, p. 105-119, 2017.

PALHARES, Pedro; GOMES, Alexandra; CARVALHO, Paulo; CEBOLO, Valter. From Teacher Education to Teacher Practice: A Gap Affecting the Implementation of Tasks. In: CLARKE, Bárbara; GREVHOLM, Barbro; MILLMAN, Richard (eds). Tasks in Primary Mathematics Teacher Education. Boston, MA: Springer, 2009. p. 275-284.

RAMOS, Taurino C. A Importância da Matemática na vida cotidiana dos alunos do ensino fundamental II. Cairu em Revista, n. 9, p. 201-218, 2017.

ROCHA, Aline L. P.; LELES, Cláudio R.; QUEIROZ, Maria G. Fatores associados ao desempenho acadêmico de estudantes de Nutrição no Enade. Revista Brasileira de Estudos Pedagógicos, v. 99, n. 251, p. 74-94, 2018.

SANTOS, Welvesley S.; GALVANIN, Edinéia Aparecida S.; CARVALHO, Jaqueline N. As Contribuições do Estudo Extra Classe nas Notas Escolares dos Alunos de uma Escola da Cidade de Barra do Bugres - Mato Grosso. Ciência e Natura, v. 39 n. 1, p. 127-132, 2017. 
SILVA, André Gustavo O. da; SALVI, Rosana. Trigonometria sem traumas: uma experiência com jogos. Revista de Educação Matemática, v. 13, n. 15, p. 27-36, 2011.

SILVA, Adriani C.; VANINI, Lucas. Investigação nos processos de ensino e de aprendizagem de funções polinomiais do 1 o grau por meio do software GeoGebra. Revista Brasileira de Ensino de Ciências e Matemática, v. 2, n. 2, p. 277-293, 2019.

SILVA JÚNIOR, João Mauro da.; COELHO, Gleide R. O ensino por investigação como abordagem para o estudo do efeito fotoelétrico com estudantes do ensino médio de um Instituto Federal de Educação, Ciência e Tecnologia. Caderno Brasileiro de Ensino de Física, v. 37, n. 1, p. 51-78, 2020.

SILVA, Lana Thais S.; AQUINO, Viviane J. B. Fração também é número?. Revista Sergipana de Matemática e Educação Matemática, n. 1, p. 68 - 81, 2019.

SILVA, Saulo Luis L. da.; FUMIÃ, Herman F. É seguro atirar para cima? Uma análise da letalidade de projéteis subsônicos. Revista Brasileira de Ensino de Física, v. 41, n. 3, 2019.

SOUZA, Rondon T. Y. B. et al. Formação continuada de professores de ciências utilizando a Aquaponia como ferramenta didática. Ciência \& Educação, v. 25, n. 2, p. 395-410, 2019.

STEWART, Ian. Em busca do infinito: uma história da Matemática dos primeiros números à teoria do caos. Rio de Janeiro: Zahar, 2014.

TABILE, Ariete F.; JACOMETO, Marisa Cláudia D. Fatores influenciadores no processo de aprendizagem: um estudo de caso. Revista Psicopedagogia, v. 34, n. 103, p. 75-86, 2017.

TARTUCE, Gisela Lobo B. P. et al. Desafios do ensino médio no brasil: iniciativas das secretarias de educação. Cadernos de Pesquisa, v. 48, n. 168, p. 478-504, 2018.

VISEU, Floriano et al. Conceções de Professores do Ensino Básico sobre a Prova Matemática: influência da experiência profissional. Boletim de Educação Matemática, v. 31, n. 57, p. 430-453, 2017.

VISEU, Floriano; ROCHA, Helena. Percepções de professores de Matemática sobre o ensino de funções e sobre o uso de materiais tecnológicos Introdução. Educação Matemática Pesquisa, v. 20, n. 2, p. 113-139, 2018. 